\title{
ON CLASSIFICATION OF THE LAND LAW PRINCIPLES
}

\author{
Anatoliy Ya. Ryzhenkov \\ Volgograd State University, Volgograd, Russian Federation
}

\begin{abstract}
Introduction. The principles of law are understood as the leading ideas, the main beginnings reflecting the essence, appointment and regularities of development of Russian law which are directly enshrined in rules of law or formulated at the doctrinal level. In both cases the value of law principles consists in the fact that they have essential influence on formation of all branches of the legislation, influence tendencies of development of law-enforcement practice. The principles of law (along with a subject and method of legal regulation) are one of criteria of division of system of the right into branches, and at identification of gaps by law-enforcement bodies in the law, can serve as means of completion of such gaps. The research object consists in complying the classification of the principles of the land law. Methods. The methodological basis of this research is represented by the set of methods of scientific knowledge among which the main place is taken by methods of the system analysis, historicism, and a comparative and legal method. Results. In work the author's position about existence of four classification groups of the principles of the land law is substantiated, inter-industry connections of land law and other branches of the law are revealed, it is proposed to reject the practice of fixing the principles of law in sublegislative acts. The system of the doctrinal principles of the land law is analyzed, the proposal on compliance of the principles of law and legal institutes is stated. Conclusions. As a result of the research it is proved that the principles of land law represent the fundamental ideas which are the cornerstone of the land law as an independent branch of the law. They define conceptual legal bases of creation, functioning and development of the land law, regulate the most important relations arising in the sphere of use and protection of lands and are protected from violations by measures of legal responsibility. At the moment the principles of the land law can be classified in inter-industry, branch, institutional; sector-forming (basic) and usual; the declarative and having the accurate mechanism realization; doctrinal (principles ideas) and set by the standard (principles norms).

Key words: principle of law, interindustry communications, land legal relationship, turnover of land plots, use and protection of lands, environment.
\end{abstract}

УДК 349.41

ББК 67.307

\section{К ВОПРОСУ О КЛАССИФИКАЦИИ ПРИНЦИПОВ ЗЕМЕЛЬНОГО ПРАВА}

\author{
Анатолий Яковлевич Рыженков \\ Волгоградский государственный университет, г. Волгоград, Российская Федерация
}

\footnotetext{
Введение: под принципами права понимаются руководящие идеи, основные начала, отражающие сущность, назначение и закономерности развития российского права, прямо закрепленные в нормах права либо сформулированные на доктринальном уровне. В обоих случаях значение принципов права состоит в том, что они оказывают существенное воздействие на формирование всех отраслей законодательства, влияют на тенденции развития правоприменительной практики. Принципы права (наряду с предметом и методом правового регулирования) являются одним из критериев деления системы права на отрасли, а при выявлении правоприменительными органами пробелов в праве могут служить средством восполнения таких пробелов. В работе поставлена цель исследования - проведение классификации принципов земельного права. Методы: методологическую основу данного исследования составляет совокупность методов научного познания, среди которых основное место занимают методы системного анализа, исто-
} 
ризма и сравнительно-правовой метод. Результаты: в работе обоснована авторская позиция о существовании четырех классификационных групп принципов земельного права, выявлены межотраслевые связи земельного и других отраслей права, предложено отказаться от практики закрепления принципов права в подзаконных актах. Проанализирована система доктринальных принципов земельного права, высказано предложение о соответствии принципов права и правовых институтов. Выводы: в результате исследования обосновано, что принципы земельного права представляют собой основополагающие идеи, лежащие в основе земельного права как самостоятельной отрасли права. Они определяют концептуальные правовые основы создания, функционирования и развития земельного права, регламентируют наиболее важные отношения, возникающие в сфере использования и охраны земель, и защищаются от нарушений мерами юридической ответственности. В настоящий момент принципы земельного права можно классифицировать на межотраслевые, отраслевые, институциональные; отраслеобразующие (базовые) и обычные; декларативные и имеющие четкий механизм реализации; доктринальные (принципы-идеи) и нормативно закрепленные (принципы-нормы).

Ключевые слова: принцип права, межотраслевые связи, земельные правоотношения, оборот земельных участков, использование и охрана земель, окружающая среда.

\section{Введение}

Традиционно под принципами права понимаются руководящие идеи, основные начала, отражающие сущность, назначение и закономерности развития российского права, прямо закрепленные в нормах права либо сформулированные на доктринальном уровне. В обоих случаях значение принципов права состоит в том, что они оказывают существенное воздействие на формирование всех отраслей законодательства, влияют на тенденции развития правоприменительной практики. Принципы права (наряду с предметом и методом правового регулирования) являются одним из критериев деления системы права на отрасли, а при выявлении правоприменительными органами пробелов в праве могут служить средством восполнения таких пробелов.

Принципы права, являясь ядром той или иной отрасли права и будучи закрепленными в законе, могут действовать непосредственно, хотя обычно в рамках каждой отрасли права предусмотрен механизм их реализации. От обычных норм права нормы-принципы отличаются более высокой степенью обобщения (абстракции), стабильностью и значимостью для регламентации определенной группы общественных отношений. Не менее важным является и ориентационная роль принципов права, позволяющая правотворческому органу сравнивать принимаемые нормы с существующими принципами.

\section{Понятие «принципы земельного права»}

На сегодняшний день нет единого универсального определения принципов земельного права. Так, Е.С. Болтанова считает, что принципы земельного права - «это объективно обусловленные характером земельных отношений основополагающие, руководящие положения, отражающие сущность земельного права» [4, с. 17-19]. Другие авторы полагают, что отличительной особенностью принципов земельного права «является их фиксация в отраслевом земельном законе - Земельном кодексе Российской Федерации» [8, с. 14]. $\mathrm{C}$ последним тезисом трудно полностью согласиться, поскольку институциональные принципы земельного права могут быть закреплены и в другом правовом акте, например, Федеральном законе «Об обороте земель сельскохозяйственного назначения».

А.С. Тютюник пишет, что под принципами земельного права следует понимать основные начала, руководящие положения, определяющие общую направленность и выражающие сущность регулирования отношений, связанных с использованием и охраной земли в Российской Федерации как основы жизни и деятельности народов, проживающих на соответствующей территории, которые, получая закрепление в актах земельного законодательства, приобретают юридическую силу нормы права $[14$, c. 93]. С последним определением следует согласиться как с наиболее полномасштабным и развернутым. 
Принципы земельного права необходимо отличать от смежных правовых явлений. Например, соотношение принципов земельного права с принципами земельной политики, в том числе с принципами земельной реформы, состоит в том, что принципы земельной политики как политические нормы могут быть основой для формирования принципов земельного права, стать обычными нормами права в форме юридических дозволений, запретов и предписаний, а также нормами-принципами земельного права, если они будут закреплены в нормативном правовом акте, а нормы-принципы - в законе [6, с. 67].

Согласно п. 2 ст. 1 ЗК РФ принципы земельного законодательства могут устанавливаться не только ЗК РФ, но и другими федеральными законами (в последнем случае это уже будут институциональные принципы). Из этого следует, что субъекты РФ не вправе устанавливать свою региональную систему принципов. Такая позиция законодателя требует корректировки. Как отмечалось в научной литературе, для повышения эффективности действующего законодательства необходимо закрепление основных общеправовых принципов разделения компетенции между Российской Федерацией и субъектами РФ, а также предоставление законодательной возможности властям регионов формировать собственную систему принципов права, отражающую основные ценности, цели и задачи правовой политики региона $[13$, с. 9$]$.

Последний вывод заслуживает поддержки еще и потому, что вопреки требованиям п. 2 ст. 1 ЗК РФ ряд принципов земельного и иного природно-ресурсного законодательства регламентируется сейчас в подзаконных актах.

Так, Постановлением Правительства РФ от 16 июля 2009 г. № 582 (ред. от 30 октября 2014 г.) «Об основных принципах определения арендной платы при аренде земельных участков, находящихся в государственной или муниципальной собственности, и о Правилах определения размера арендной платы, а также порядка, условий и сроков внесения арендной платы за земли, находящиеся в собственности Российской Федерации» закреплен ряд таких принципов (принцип экономической обоснованности, принцип предсказуемости расчета размера арендной платы, принцип предельно допустимой простоты расчета арендной платы и т. д.), которые конкретизируют действие межотраслевого принципа платности использования земли. Аналогичная ситуация и в других отраслях природно-ресурсного права. Так, в рамках горного права Постановление Правительства РФ от 30 января 2016 г. № 48 «О федеральной государственной информационной системе "Единый фонд геологической информации о недрах"» определяет принципы создания и эксплуатации такой информационной системы; в водном праве Постановлением Правительства РФ от 14 декабря 2006 г. № 764 «Об утверждении Правил расчета и взимания платы за пользование водными объектами, находящимися в федеральной собственности» утверждены принципы установления такой платы. Этот перечень может быть продолжен.

\section{Классификация принципов земельного права}

Как и любое сложное общественное явление, принципы права могут быть классифицированы в несколько групп. Проведение таких классификаций имеет высокое познавательное значение, позволяющее выявить закономерности изучаемого явления и лучше узнать его основные свойства. Классификация - это особый случай применения логической операции деления объема понятия, выявления сходства и различия между предметами. Наряду с этим целью классификации может являться и систематизация предметов. Всякая классификация является результатом некоторого огрубления действительных граней между ее объектами, она всегда условна и относительна. С развитием знаний происходит уточнение и изменение классификации. Важным принципом классификации является принцип объективности. Он определяет содержание всех остальных принципов и отражает сущность классифицируемых явлений. Объективность обусловлена всесторонностью и конкретностью, ее цель - познание явления таким, каково оно есть в реальности [3, с. 88-92].

На сегодняшний день общепризнанной классификации принципов земельного права нет. В рамках науки теории государства и пра- 
ва предлагается классифицировать правовые принципы на общесоциальные и специальноюридические. В свою очередь среди общесоциальных принципов С.С. Алексеев выделял социально-экономические, политические, идеологические, политико-национальные и нравственные начала, а непосредственно к правовым относил общие для системы права в целом, отраслевые, межотраслевые и принципы отдельных институтов права [1, с. 262263]. В дополнение к этому Г.А. Свердлык, кроме общеправовых, межотраслевых, отраслевых и принципов институтов права, предлагал рассматривать в качестве самостоятельных подотраслевые и межинституционные нормативно-руководящие начала $[10$, с. 6568]. Исходя из этого представляется, что по разным критериям принципы земельного права могут быть классифицированы в несколько подгрупп:

1. Учитывая, что общеправовые принципы не имеют в рамках земельного права никакой специфики, а подотраслей в земельном праве нет, общераспространенная классификация принципов земельного права имеет следующий вид: межотраслевые принципы, отраслевые, институциональные. Критерием такого деления служит сфера распространения принципов земельного права. Такая классификация позволяет показать объем регулирующего воздействия принципов земельного права на общественные отношения и специфику их проявления в рамках отдельных институтов земельного права.

Межотраслевой принцип права - это общая для двух и более отраслей права России основная идея, отражающая закономерности и связи развития общественных отношений, нормативно закрепленная в позитивном праве, направляющая правовое регулирование и определяющая сущность и социальное назначение права. Эти принципы не дают отраслям права существовать обособленно друг от друга, поскольку через них происходит координация взаимодействия отраслей российского права между собой. Межотраслевые принципы права проявляют себя в сходных правовых отношениях. Учет межотраслевого единства в содержании принципов имеет важное практическое значение, ибо позволяет полнее выявлять как общие, так и специфические черты этих принципов, что очень важно для правоприменения [7, с. 7-17].

Как отмечал Г.А. Волков, существует две группы межотраслевых принципов земельного права. Межотраслевой характер первой группы принципов земельного права проявляется при их соприкосновении с иными природно-ресурсными отраслями права, гражданским правом, правовыми нормами законодательства о градостроительстве, отраслями права, содержащими правовые нормы об использовании недвижимости. Во вторую группу включены случаи соприкосновения земельного и экологического права [5, c. 18]. С данной позицией следует согласиться лишь отчасти. Дело в том, что кроме имущественных отношений (отношений недвижимости), общие правила регулирования которых определяют межотраслевые принципы, образованные на пересечении сферы действия земельного, гражданского и градостроительного права, а также межотраслевых принципов, относящихся к охране природных объектов (в сфере действия земельного, водного, горного, лесного и экологического права), существует еще блок административных принципов и норм, касающихся вопросов управления природопользованием.

С некоторой долей условности в него можно включить принцип платности использования земель. В рамках такого блока межотраслевых принципов права сосуществуют принципы и нормы, имеющие «двойную прописку» в административном и финансовом праве, с одной стороны, и в отраслях природно-ресурсного права - с другой. Наконец, в еще один (четвертый) межотраслевой блок входят межотраслевые принципы, существующие только в рамках отраслей (реже подотраслей) природно-ресурсного права.

К межотраслевым принципам земельного права относится приоритет охраны земли как важнейшего компонента окружающей среды и средства производства в сельском и лесном хозяйстве перед использованием земли в качестве недвижимого имущества (это межотраслевой принцип земельного и экологического права); приоритет сохранения особо ценных земель и земель особо охраняемых территорий (земельного и экологического права); платность использования земли (земель- 
ного и финансового права); участие граждан, общественных организаций (объединений) и религиозных организаций в решении вопросов, касающихся их прав на землю (земельного и конституционного права); разграничение государственной собственности на землю на собственность Российской Федерации, собственность субъектов Российской Федерации и собственность муниципальных образований (межотраслевой принцип земельного и гражданского права) и т. д.

Под отраслевыми принципами права обычно понимаются принципы, действующие в рамках только одной отрасли права, характеризующие наиболее существенные ее черты и свойства. Такие принципы обусловлены спецификой соответствующих предметов и методов правового регулирования. В рамках земельного права к таким отраслевым принципам следует отнести, например, принцип деления земель по целевому назначению на категории или дифференцированный подход к установлению правового режима земель.

Институичиональные принципы земельного права (на уровне правовых институтов) закрепляют наиболее характерные черты этих структурных подразделений земельного права России. Значение земельно-правовых институтов состоит в том, что они образуют совокупность взаимосвязанных норм, peгулирующих качественно однородные общественные отношения. В каждой отрасли права есть несколько институциональных принципов. В рамках земельного права к их числу относятся, например, принципы оборота земель сельскохозяйственного назначения или принципы ведения Государственного кадастра недвижимости и Единого государственного реестра недвижимости.

2. По критерию роли и значения (важности для развития отрасли) можно выделить «отраслеобразующие» принципы земельного права, к числу которых относятся: а) принцип учета значения земли как основы жизни и деятельности человека, б) приоритет охраны жизни и здоровья человека при использовании и охране земель, в) приоритет охраны земли как важнейшего компонента окружающей среды и средства производства в сельском и лесном хозяйстве перед использованием земли в качестве недвижимого имущества. Они стоят на первом месте в ЗК РФ не случайно, поскольку обеспечивают стабильность земельных отношений и все остальные принципы зависят от их реализации или ее обеспечивают. Данные принципы отражают главную задачу всей отрасли земельного права России - обеспечение охраны земли и ее рационального использования гражданами и их объединениями. Особенностью земельного права является стабильность его основных принципов при постепенной трансформации развивающих их институтов.

Наряду с базовыми, «отраслеобразующими» принципами необходимо выделить принципы земельного права «второго порядка», имеющие более узкий смысл и носящие характер скорее принципов правового регулирования, поскольку они не имеют такого смыслообразующего значения для отрасли земельного права. Они обеспечивают правопорядок в той или иной более локальной сфере земельных отношений. К ним можно отнести: принцип участия граждан, общественных организаций (объединений) и религиозных организаций в решении вопросов, касающихся их прав на землю; принцип единой судьбы земельных участков и прочно связанных с ними объектов; приоритет сохранения особо ценных земель и земель особо охраняемых территорий; платность использования земли; деление земель по целевому назначению на категории; разграничение государственной собственности на землю на собственность Российской Федерации, собственность субъектов Российской Федерации и собственность муниципальных образований; дифференцированный подход к установлению правового режима земель; сочетание интересов общества и законных интересов граждан; принцип разграничения действия норм гражданского законодательства и норм земельного законодательства в части регулирования отношений по использованию земель, а также принцип государственного регулирования приватизации земли.

Таким образом, по данному критерию система принципов земельного права включает три отраслеобразующих принципа, выступающих ее «основным ядром», и серию более локальных принципов, сформулированных более конкретно и предназначенных для решения прикладных правовых задач. 
3. По критерию степени востребованности и качеству механизма реализации принципы земельного права можно классифицировать на декларативные принципы и принципы с четким механизмом реализации, которые постоянно применяются на практике. На последние принципы часто ссылаются суды, рассматривая те или иные категории дел. К числу таких принципов можно отнести принцип платности использования земли или принцип деления земель по целевому назначению на категории. Типичным примером декларативных принципов является принцип участия граждан, общественных организаций (объединений) и религиозных организаций в решении вопросов, касающихся их прав на землю. Для его реализации сам ЗК РФ упоминает лишь «общественные слушания», проводимые при установлении публичных сервитутов. Другого механизма реализации данного принципа в ЗК РФ нет.

4. Принципы земельного права, прямо закрепленные в земельном законодательстве России (принципы-нормы) и доктринально выводимые (принципы-идеи) или, другими словами, писаные и неписаные принципы. В теории права и государства традиционно считается, что система принципов права носит «объективный характер», а система принципов законодательства «субъективна» и зависит от усмотрения законодателя [11, с. 145 147]. Между тем не существует критериев такой «объективности», поскольку у каждого специалиста в области земельного (или любого иного) права будет свой набор «объективных» принципов земельного права, тогда как набор «субъективных принципов» законодательно закреплен, существует объективно и может быть подвержен анализу. Другое дело, что доктринальное обсуждение системы «объективно существующих» принципов права (в том числе земельного права) влияет на законодательные решения. Именно поэтому, если говорить о каком-то общепризнанном наборе принципов, то таковым являются принципы законодательства. Соответственно, в своей доктринальной части, не получившей подтверждения в законе, принципы права не совпадают, они шире принципов законодательства. В остальной же части они тождественны.

Какого-либо общепринятого перечня доктринально выводимых и предлагаемых зако- нодателю принципов земельного права не существует. Так, Г.А. Волков упоминает в числе межотраслевых принципы экологизации земельного права; планирования использования земель; комплексного подхода в использовании земель; обеспечения рационального использования и охраны земель; платности использования земель; подконтрольности использования земель государству [5, с. 20]. Из этого перечня в ЗК РФ и других актах земельного законодательства прямо предусмотрен только принцип платности.

Э.Ф. Нигматуллина упоминает принцип «наименьшего действия», под которым понимается законодательный подход, направленный на причинение наименьшего беспокойства (и ущерба) собственнику участка при установлении сервитута либо при использовании для разработки полезных ископаемых, прежде всего участков, не занятых лесами (гари, вырубки и т. д.). Другой такой принцип сформулирован в решениях Европейского суда по правам человека и может быть назван «принципом правомерного ожидания», предполагающим возможность защиты прав на имущество в том случае, когда у лица отсутствовал титул на это имущество, но имелось обоснованное «правомерное» или «законное ожидание», связанное с таким имуществом [9, с. 63-124].

По данному вопросу есть и другие предложения. Представляется логичным предположить, что принципы права должны «пронзать» всю отрасль права, поскольку они общепризнанно выступают в роли базовых (исходных) начал любой отрасли права. Между тем даже поверхностный взгляд на Земельный кодекс свидетельствует, что одни указанные в ст. 1 ЗК РФ принципы имеют механизм реализации (то есть имеются нормы, определяющие порядок практического осуществления заложенных в этих принципах правовых предписаний), а другие нет. Есть и обратная ситуация - в ЗК РФ представлен ряд правовых институтов, которые не охвачены принципами права. Типичный пример - это институты управления земельным фондом, ответственности за земельные правонарушения, ряд институтов особенной части земельного права (например, стоит упомянуть категории земель промышленности и иного специального 
назначения и земель водного фонда). Между тем в идеале основным институтам (или даже субинститутам) должен корреспондировать хотя бы один межотраслевой, отраслевой или институциональный принцип земельного права. Несомненно, перечень институтов земельного права не имеет однозначного понимания, хотя все авторы, которые пишут о системе земельного права, полностью согласны с перечнем институтов особенной части земельного права (семь категорий земель - семь институтов особенной части). По общей части такого единства мнений нет. Однако в любом случае ситуация, когда одним институтам земельного права корреспондирует принцип (а нормы данного института содержат механизм его реализации), а другим институтам нет, неправильная. Думается, что сложившаяся ситуация нарушает логику построения системы принципов земельного права.

Не менее примечательно, что некоторые институты земельного права представлены принципами лишь частично и только на институциональном уровне. Например, Федеральный закон «Об обороте земель сельскохозяйственного назначения» от 24 июля 2002 г. № 101-Ф3 содержит принципы оборота земель сельскохозяйственного назначения, то есть всего одной категории земель в земельном фонде страны. Между тем другие категории земель тоже в той или иной степени находятся в гражданском обороте (земли населенных пунктов даже с меньшими ограничениями) [2, c. 63-68], однако по отношению к ним законодатель не предусмотрел никаких земельных принципов.

Таким образом, доктринальные принципы - это принципы, которые прямо не указаны в земельном законодательстве, но следуют из смысла и содержания его нормативных правовых актов. Такие принципы не обладают юридической силой и формулируются учеными путем толкования норм земельного права. Изначально являясь идеями, они отражают суть сложившихся в обществе отношений и затем могут получить нормативное закрепление [14, с. 95].

В состав доктринальных принципов земельного права следует включить как минимум принцип управления земельным фондом, принцип ответственности за земельные пра- вонарушения и принцип экологизации. Некоторые институциональные принципы в дальнейшем надо расширить до межотраслевого уровня, например, принцип нахождения земельных участков в гражданском обороте (всех земельных участков, а не только участков сельскохозяйственного назначения). В этом случае это будет межотраслевой принцип, реализуемый в нормах земельного и гражданского законодательства.

При этом следует поддержать высказанную в научной литературе позицию о том, что в кодифицированные нормативные акты (включая и Земельный кодекс) целесообразно включать специальную статью, указывающую на необходимость при толковании и применении закона основываться на принципах права. Формулировка такой статьи может выглядеть следующим образом: «Применение норм ... законодательства должно осуществляться с учетом принципов права, закрепленных в Конституции РФ, настоящем Кодексе, а также иных признанных в российской правовой системе принципов права, в том числе общепризнанных принципов международного права» $[12$, с. 10$]$.

\section{Выводы}

Проведенное исследование позволяет сформулировать следующие выводы. Принципы земельного права представляют собой основополагающие идеи, лежащие в основе земельного права как самостоятельной отрасли права. Они определяют концептуальные правовые основы создания, функционирования и развития земельного права, регламентируют наиболее важные отношения, возникающие в сфере использования и охраны земель, и защищаются от нарушений мерами юридической ответственности. В настоящий момент принципы земельного права можно классифицировать на межотраслевые, отраслевые, институциональные; отраслеобразующие (базовые) и обычные; декларативные и имеющие четкий механизм реализации; доктринальные (принципы-идеи) и нормативно-закрепленные (принципы-нормы).

Рассмотрение принципов земельного права как системного явления позволяет выявить межотраслевые связи земельного и иных отраслей права, показать сущность ис- 
следуемых явлений, подчеркнуть взаимосвязь и взаимовлияние всех групп земельных принципов друг на друга, определить цели и задачи земельного права в современных условиях развития государства.

\section{СПИСОК ЛИТЕРАТУРЫ}

1. Алексеев, С. С. Общая теория права. В 2 т. Т. 1 / С. С. Алексеев. - М. : БЕК, 1981. -355 с.

2. Анисимов, А. П. Управление земельными ресурсами в целях вовлечения земельных участков в экономический оборот / А. П. Анисимов, Г. Л. Землякова // Право и экономика. -2012. -№ 8. C. 63-68.

3. Болдырев, С. Н. Общетеоретические средства юридической техники / С. Н. Болдырев // Научный вестник Волгоградской академии государственной службы. - 2012. - № 1. - С. 88-92.

4. Болтанова, Е. С. Земельное право / Е. С. Болтанова. - М. : Инфра-М, 2010. - 553 с.

5. Волков, Г. А. Принципы земельного права : автореф. дис. ... д-ра юрид. наук / Волков Геннадий Александрович. - М., 2005. - 52 с.

6. Волков, Г. А. Принципы земельного права как важнейший элемент эколого-правового механизма (в развитие идей В.В. Петрова) / Г. А. Волков // Экологическое право. - 2009. - № 2/3. - С. 60-68.

7. Захаров, А. Л. Межотраслевые принципы права : автореф. дис. ... канд. юрид. наук / Захаров Алексей Леонидович. - Казань, 2003. - 34 с.

8. Земельное право : учебник / под ред. С. А. Боголюбова. - М. : Проспект, 2010. - 400 с.

9. Нигматуллина, Э. Ф. Нормообразующие факторы, влияющие на осуществление прав на земельные участки / Э. Ф. Нигматуллина. - Казань : Изд-во Казанского университета, 2016. - 494 с.

10. Свердлык, Г. А. Принципы гражданского права / Г. А. Свердлык. - Красноярск : Изд-во Красноярского университета, 1985. - 200 с.

11. Сенякин, И. Н. Федерализм как принцип российского законодательства / И. Н. Сенякин. - Саратов : Саратовская государственная академия права, 2007. -504 c.

12. Сидоркин, А. С. Принципы права: понятие и реализация в российском законодательстве и судебной практике : автореф. дис. ... канд. юрид. наук / Сидоркин Александр Сергеевич. - М., 2010. - 25 с.

13. Степаненко, Р. А. Теоретико-правовые аспекты разграничения предметов ведения между Российской Федерацией и ее субъектами в сфере земельного законодательства : дис. ... канд. юрид. наук / Степаненко Рустам Алиевич. - Ставрополь, 2012.-199 c.
14. Тютюник, А. С. Система принципов земельного права в современных условиях / А. С. Тютюник // Юридическая наука. - 2014 - - № 3. - С. 91-96.

\section{REFERENCES}

1. Alekseev S.S. Obshchaya teoriya prava. T. 1 [The General Theory of Law. Vol. 1]. Moscow, 1981. $355 \mathrm{p}$.

2. Anisimov A.P., Zemlyakova G.L. Upravlenie zemelnymi resursami $\mathrm{v}$ tselyakh vovlecheniya zemelnykh uchastkov $\mathrm{v}$ ekonomicheskiy oborot [Management of Land Resources for Involvement of Land Plots in Economic Circulation]. Pravo $i$ ekonomika, 2012, no. 8, pp. 63-68.

3. Boldyrev S.N. Obshcheteoreticheskie sredstva yuridicheskoy tekhniki [General Theoretical Means of the Legal Technique]. Nauchnyy vestnik Volgogradskoy akademii gosudarstvennoy sluzhby, 2012, no. 1, pp. 88-92.

4. Boltanova E.S. Zemelnoe pravo: uchebnik [Land Law: Textbook]. Moscow, 2010.553 p.

5. Volkov G.A. Printsipy zemelnogo prava: avtoref. ... dis. d-ra yurid. nauk [Principles of the Land Law. Dr. jurid. sci. abs. diss.]. Moscow, 2005. 52 p.

6. Volkov G.A. Printsipy zemelnogo prava kak vazhneyshiy element ekologo-pravovogo mekhanizma (v razvitie idey V.V. Petrova) [The Principles of the Land Law as the Most Important Element of an Ecological Legal Mechanism (in Development of V.V. Petrov's Ideas)]. Ekologicheskoe pravo, 2009, no. 2/3, pp. 60-68.

7. Zakharov A.L. Mezhotraslevye printsipy prava: avtoref. dis. ... kand. yurid. nauk [Intersectoral Principles of Law. Cand. jurid. sci. abs. diss.]. Kazan, 2003. 34 p.

8. Bogolyubov S.A. Zemelnoe pravo: uchebnik [Land Law: Textbook]. Moscow, Prospectus Publ., 2010. 400 p.

9. Nigmatullina E.F. Normoobrazuyushchie faktory, vliyayushchie na osushchestvlenie prav na zemelnye uchastki [Norm-Forming Factors Influencing Implementation of the Rights to Land Plots]. Kazan, 2016. 494 p.

10. Sverdlyk G.A. Printsipy grazhdanskogo prava [Principles of Civil Law]. Krasnoyarsk, 1985. 200 p.

11. Senyakin I.N. Federalizm kak printsip rossiyskogo zakonodatelstva [Federalism as a Principle of the Russian Legislation]. Saratov, 2007. $504 \mathrm{p}$.

12. Sidorkin A.S. Printsipy prava: ponyatie $i$ realizatsiya $v$ rossiyskom zakonodatelstve i sudebnoy praktike: avtoref. dis. ... kand. yurid. nauk [Principles of Law: Concept and Implementation in the Russian Legislation and Court Practice. Cand. jurid. sci. abs. diss.]. Moscow, 2010. 25 p. 
13. Stepanenko R.A. Teoretiko-pravovye aspekty razgranicheniya predmetov vedeniya mezhdu Rossiyskoy Federatsiey $i$ ee subyektami v sfere zemelnogo zakonodatelstva: dis. ... kand. yurid. nauk [Theoretical and Legal Aspects of Differentiation of Jurisdiction Areas between the Russian Federation and
Its Subjects in the Sphere of the Land Legislation. Cand. jurid. sci. diss.]. Stavropol, 2012. 199 p.

14. Tyutyunik A.S. Sistema printsipov zemelnogo prava $\mathrm{v}$ sovremennykh usloviyakh [The System of Land Law Principles in the Modern Conditions]. Yuridicheskaya nauka, 2014, no. 3, pp. 91-96.

\section{Information About the Author}

Anatoliy Ya. Ryzhenkov, Doctor of Juridical Sciences, Professor, Department of Civil and International Private Law, Volgograd State University, Base Department of the Southern Scientific Center of the Russian Academy of Sciences, Prosp. Universitetsky, 100, 400062 Volgograd, Russian Federation, 4077778@list.ru, gimchp@volsu.ru.

\section{Информация об авторе}

Анатолий Яковлевич Рыженков, доктор юридических наук, профессор кафедры гражданского и международного частного права, Волгоградский государственный университет, базовая кафедра ЮНЦ РАН, просп. Университетский, 100, 400062 г. Волгоград, Российская Федерация, 4077778@list.ru, gimchp@volsu.ru. 